Pak. J. Agri. Sci., Vol. 55(1), 1-12; 2018

ISSN (Print) 0552-9034, ISSN (Online) 2076-0906

DOI: $10.21162 / P A K J A S / 18.6215$

http://www.pakjas.com.pk

\title{
TREATMENT STRENGTH OPTIMIZATION FOR MAIZE (Zea mays L.) AGAINST SALINE CONDITIONS USING BIPLOT ANALYSIS
}

\author{
Khalil Ahmad $^{1}$, Muhammad Aslam ${ }^{1}{ }^{*}$, Muhammad Imtiaz ${ }^{2}$, Muhammad Ahsan ${ }^{1}$ and \\ Muhammad Farrukh Saleem ${ }^{3}$
}

\author{
${ }^{1}$ Department of Plant Breeding and Genetics, University of Agriculture, Faisalabad, Pakistan; ${ }^{2}$ Country Laison \\ Officer, CIMMYT, Pakistan; ${ }^{3}$ Department of Agronomy, University of Agriculture, Faisalabad, Pakistan. \\ *Corresponding author's e-mail: aslampbg@gmail.com
}

\begin{abstract}
Maize (Zea mays L.) genotypes collected from different research institutes were evaluated against different standards associated with salinity tolerance/susceptibility under four variable saline treatment strengths $\mathrm{S}_{0.8 \mathrm{dSm}^{-1}}\left(\mathrm{~T}_{1} ;\right.$ Control), $\mathrm{S}_{4 \mathrm{dSm}^{-1}}$ $\left(\mathrm{T}_{2}\right), \mathrm{S}_{6 \mathrm{dSm}}{ }^{-1}\left(\mathrm{~T}_{3}\right)$ and $\mathrm{S}_{10 \mathrm{dsm}}{ }^{-1}\left(\mathrm{~T}_{4}\right)$ to optimize treatment strengths for screening and to study genotype $\times$ environment interaction (GEI) on the basis of shoot length (SL), root length (RL), shoot fresh weight (SFW), shoot dry weight (SDW), root fresh weight (RFW), root dry weight (RDW), sodium concentration in leaf sap $\left(\mathrm{Na}^{+}\right)$, chloride concentration in leaf sap $\left(\mathrm{Cl}^{-}\right)$, potassium concentration in leaf sap $\left(\mathrm{K}^{+}\right)$, total proline contents in leaf sap (PRO) and sodium/potassium ratio $\left(\mathrm{Na}^{+} / \mathrm{K}^{+}\right)$. Under $\mathrm{S}_{10} \mathrm{dsm}^{-1}$, genotype UAC-0020 performed relatively well based on $\mathrm{Na}^{+}$and $\mathrm{Cl}^{-}$whereas UAC-0036 performed well for $\mathrm{K}^{+}$and $\mathrm{Na}^{+} / \mathrm{K}^{+}$.

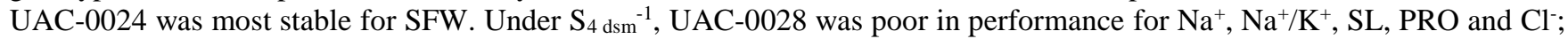
similarly, UAC-0048 showed poor performance for SFW, RFW, SL and PRO; UAC-0041 and UAC-0033 posed least resistance for SL, SFW, RL and RFW, respectively. The rest of the genotypes interacted under all the variable stressful environments either positively or negatively. SL, SDW, RFW, $\mathrm{Na}^{+}, \mathrm{Cl}^{-}$and $\mathrm{PRO}$ were verified as very good indicators of salinity tolerance in maize plant. Biplot based on Principal Component Analysis (PCA) is reported as an effective technique to study GEI. $\mathrm{S}_{4 \mathrm{dsm}}{ }^{-1}$ was proved as best strength to sort out susceptible and $\mathrm{S}_{10 \mathrm{dsm}}{ }^{-1}$ to sort out most tolerant genotypes. The best performing genotypes could be considered for further breeding programs.
\end{abstract}

Keywords: Maize genotypes, salinity treatments, hydroponics, biplot analysis, optimization.

\section{INTRODUCTION}

Demand to fulfill the needs of the people is increasing with continuous increase in population but yield is decreasing due to some problematic causes especially biotic and abiotic stresses. The most deleterious factor among abiotic is salinity. Salinity is pervasive threat to crop production predominantly in countries where supplement irrigation is needed. Mostly the water on earth is salty, comprising $30 \mathrm{~g}$ of $\mathrm{NaCl}$ per liter, which is constantly affecting the soil on which crops are/or might be grown (Flowers, 2004). It is estimated that almost $15 \%$ of the total land is badly affected by salt in the world (Akram et al., 2010), which reduces the yield potential of approximately 20 Mha of the land each year.

Among salts, $\mathrm{NaCl}$ is leading one in saline lands. Salt-induced growth drop happens in two junctures; immediate response due to aggregation of too much salt in root regions and slow response with respect to the gathering of salts to poisonous level in leaves (Arzani, 2008). Root zone sodicity varies ionic and plant water status as plants unable to take water due to low soil water potential established by unnecessary salt in the rhizospheric solution (Munns et al. 2006). Furthermore, salinity stress builds up of $\mathrm{Na}^{+}$and $\mathrm{Cl}^{-}$ions to lethal level which in turn inhibits absorption and supply of vital mineral nutrients like $\mathrm{N}, \mathrm{P}, \mathrm{K}^{+}$and $\mathrm{Ca}^{+2}$ to physiologically active zones of plants (Chinnusamy et al., 2005). A high salt substance in root zone disturbs maize growth and ultimately, happens a severe reduction in its harvest (Munns, 2002), by bringing low osmotic potential (Ashraf, 2004), hindering enzyme activities, distressing solute accumulation (Flowers, 2004), making ionic imbalance (Barnard et al., 2010), fluctuating plant metabolic activities, varying cellular level, altering biochemical and physiological processes (Najafi et al., 2007), dropping water potential, poisoning with $\mathrm{Na}^{+}$ions (Munns and Tester, 2008), and disturbing the absorption of essential nutrients (Akram et al., 2007), or due to with all these issues. In addition to ionic and osmotic stress, salinity prompts unnecessary production of reactive oxygen species (ROS) such as singlet oxygen, hydrogen peroxide, superoxide and hydroxyl radical (Verma and Mishra, 2005) which denature macromolecules and peroxidize membrane lipids which ruins the plant's metabolism (Mittler, 2002).

Cultivation of salt tolerant plants is best strategy regarding usage of salt affected soils (Ashraf, 1994). It is most practicable and economical. Screening of germplasm of crop plants is prerequisite to categorize salt tolerant genotypes for any breeding program. 
Internationally, maize (Zea mays L.) is the $3^{\text {rd }}$ most essential food crop after wheat and rice, both in terms of area and production. It is also known as queen of cereals due to high yield potential. In addition to this, a large proportion of population in the world depends on it for food. In Pakistan, it was cultivated on 1.144 million hectares and its production was of 4.920 million tons (Govt. of Pakistan, 2015).

The objectives of this study were to assess the extent of adaptability, variability of maize germplasm against variable saline environments to identify salt tolerant and sensitive germplasm and to work out the best selection standard against salinity stress.

\section{MATERIALS AND METHODS}

Research experiment was conducted in the screenhouse of the department of Plant Breeding and Genetics, University of Agriculture Faisalabad, Punjab, Pakistan (latitude $=31^{\circ}-30^{\prime}$ $\mathrm{N}$, longitude $=73^{\circ}-10^{\prime} \mathrm{E}$ and altitude $\left.=184.4 \mathrm{~m}\right)$. Total 40 maize genotypes namely UAC-0013 through UAC-0052 were used in current study. Maize genotypes were sown in germination trays filled with distilled water washed sand. After 15 days of sowing, uniform maize seedlings were transplanted to aquaculture which consisted of sheet of polystyrene floating on $1 / 2$ strength Hoagland's nutrient solution medium with proper aeration system. Strength of Hoagland nutrient solution was improved up to full strength after two days. Seedlings were allowed to stabilize for three days in hydroponic medium. After three days, four treatments like $\mathrm{S}_{0.8 \mathrm{dSm}^{-1}}\left(\mathrm{~T}_{1}\right.$; Control), $\mathrm{S}_{4 \mathrm{dSm}^{-1}}\left(\mathrm{~T}_{2}\right), \mathrm{S}_{6 \mathrm{dSm}}{ }^{-1}\left(\mathrm{~T}_{3}\right)$ and $\mathrm{S}_{10}$ $\mathrm{dsm}^{-1}\left(\mathrm{~T}_{4}\right)$ were applied by using $\mathrm{NaCl}$. Initially half strength stress was applied which was made full strength after 3 days.
Experiment was carried out by following triplicated completely randomized design in split plot arrangement. $\mathrm{pH}$ of the hydroponic solution was maintained at $7.0 \pm 0.5$ on daily basis by using $\mathrm{NaOH}$ and $\mathrm{HCl}$. After 32 days of transplanting, seedlings were harvested to record data of shoot length $(\mathrm{cm})$, root length $(\mathrm{cm})$, shoot fresh weight (g/plant), shoot dry weight (g/plant), root fresh weight (g/plant), root dry weight (g/plant), $\mathrm{Na}^{+}$concentration $\left(\right.$mole $\left.\mathrm{m}^{-3}\right), \mathrm{K}^{+}$concentration $\left(\right.$ mole $\left.\mathrm{m}^{-3}\right), \mathrm{Cl}^{-}$concentration $\left(\right.$mole $\left.\mathrm{m}^{-3}\right)$, proline contents $(\mu$ mol g ${ }^{-1}$ ) and $\mathrm{Na}^{+} / \mathrm{K}^{+}$.

Statistical analysis: Data were analyzed for significance of treatment differences among genotypes using analysis of variance (Steel et al., 1997). Variability in genotypes against salinity in each trait was studied by biplot based on principal component analysis (PCA).

\section{RESULTS}

The effects of treatment, genotypes and interaction between treatment and genotypes were found significant $(\mathrm{P}<0.05)$ for all the studied morphological and physiological traits (Table 1). Variation in $\mathrm{Na}^{+} / \mathrm{K}^{+}$ratio among all the genotypes was assessed by different regions of principal component-1 $\left(\mathrm{PC}_{1}\right)$ and principal component-2 $\left(\mathrm{PC}_{2}\right)$ under four salinity levels $\left(\mathrm{S}_{0.8 \mathrm{dsm}}{ }^{-1}, \mathrm{~S}_{4 \mathrm{dsm}}{ }^{-1}, \mathrm{~S}_{6 \mathrm{dsm}}{ }^{-1}\right.$ and $\left.\mathrm{S}_{10 \mathrm{dsm}^{-1}}\right)$; which showed most precise and reliable results than other PCs due to contribution of highest interaction percentage (83.80). Individually, $\mathrm{PC}_{1}$ and $\mathrm{PC}_{2}$ revealed $58.76 \%$ and $25.04 \%$ interaction towards variation. There were two values of each principal component (PC), positive and negative. The four vectors (salinity treatments) along two axes were not perpendicular had strong discrimination power for explaining

Table 1. Mean squares with respective levels of significance for different traits in maize at different salinity levels.

\begin{tabular}{lccccccc}
\hline SOV & DF & SL & RL & SFW & SDW & RFW & RDW \\
\hline Replication & 2 & 0.4 & 0.5 & 1.05 & 0.13 & 0.1 & 0.01 \\
Treatment & 3 & $2704.14^{*}$ & $3026.9^{*}$ & $594.9^{*}$ & $22.25^{*}$ & $34^{*}$ & $6.01^{*}$ \\
Error Replication*Treatment & 6 & 5.0 & 1.8 & 2.6 & 0.3 & 0.4 & 0.04 \\
Genotype & 39 & $186.16^{*}$ & $65.8^{*}$ & $12.55^{*}$ & $1.2^{*}$ & $1.8^{*}$ & $0.1^{*}$ \\
Treatment*Genotype & 117 & $55.7^{*}$ & $17.3^{*}$ & $3.35^{*}$ & $0.3^{*}$ & $0.7^{*}$ & $0.03^{*}$ \\
Error Replication*Treatment*Genotype & 312 & 327.1 & 191.5 & 104.06 & 8.6 & 14.6 & 3.5 \\
Total & 479 & & & & & \\
SOV & $\mathbf{D F}$ & $\mathbf{N a}^{+}$ & $\mathbf{K}^{+}$ & $\mathbf{C l}$ & $\mathbf{P R O}$ & $\mathbf{N a}^{+} / \mathbf{K}^{+}$ \\
Replication & 2 & 0.2 & 2.3 & 0.09 & 0.1 & 0.0008 \\
Treatment & 3 & $11685.5^{*}$ & $4829.6^{*}$ & $4766.7^{*}$ & $60.3^{*}$ & $18.30^{*}$ \\
Error Replication*Treatment & 6 & 3.4 & 18.1 & 8.0 & 0.16 & 0.008 \\
Genotype & 39 & $234^{*}$ & $145.55^{*}$ & $69.0^{*}$ & $1.8^{*}$ & $0.80^{*}$ \\
Treatment*Genotype & 117 & $101.7^{*}$ & $56.2^{*}$ & $27.6^{*}$ & $0.9^{*}$ & $0.30^{*}$ \\
Error Replication*Treatment*Genotype & 312 & 169.2 & 278.2 & 398.3 & 13.7 & 0.30 \\
Total & 479 & & & & & & \\
\hline
\end{tabular}

*denotes highly significant differences $(\mathrm{P}<0.01)$

Abbreviations: SL; shoot length, RL; root length, SFW; shoot fresh weight, SDW; shoot dry weight, RFW; root fresh weight, RDW; root dry weight, $\mathrm{Na}^{+}$; sodium concentration, $\mathrm{K}^{+}$; potassium concentration, $\mathrm{Cl}^{-}$; chloride concentration, $\mathrm{PRO}$; proline contents, $\mathrm{Na}^{+} / \mathrm{K}^{+}$; sodium/potassium ratio. 
variability with respect to genotypes UAC-0028, UAC-0033, UAC-0041 and UAC-0048 decided to go towards the heads of environment vectors away from origin of graph (positive value region) while UAC-0020, UAC-0024 and UAC-0036 scattered opposite to saline vectors apart from origin of graph (negative value region) for $\mathrm{Na}^{+} / \mathrm{K}^{+}$(Fig. 1).

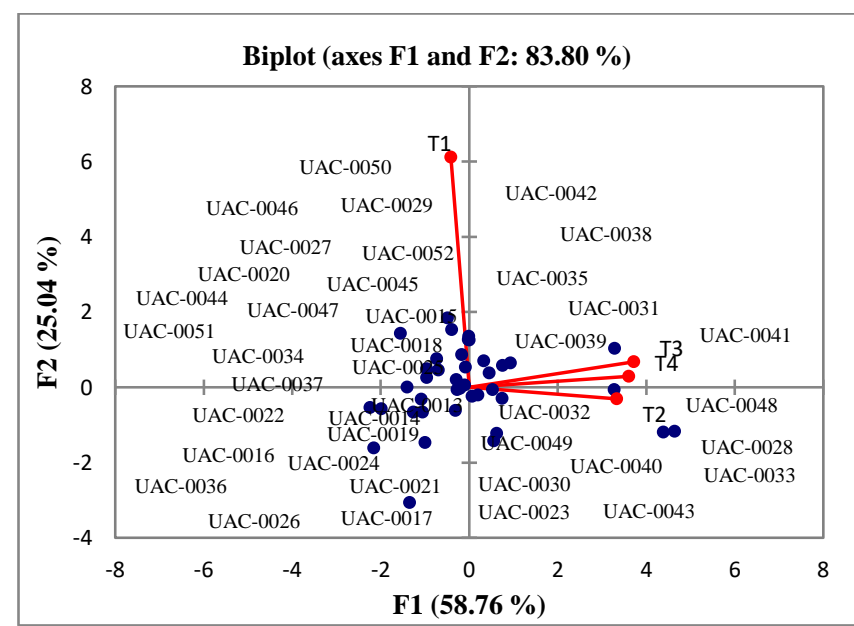

Figure 1. PCA Biplot for $\mathrm{Na}^{+} / \mathrm{K}^{+}$.

Spoke lengths of $\mathrm{S}_{4 \mathrm{dsm}^{-1}}, \mathrm{~S}_{6 \mathrm{dsm}^{-1}}$ and $\mathrm{S}_{10 \mathrm{dsm}}{ }^{-1}$ vectors were approximately same which indicated that concerned vectors had the same interactive force for genotypes. Angles between the $\mathrm{S}_{4 \mathrm{dsm}}{ }^{-1}, \mathrm{~S}_{6 \mathrm{dsm}}{ }^{-1}$ and $\mathrm{S}_{10 \mathrm{dsm}^{-1}}$ vectors were small which resulted that genotypes responded similarly in all stress environments. Spoke length of $\mathrm{S}_{0.8 \mathrm{dsm}^{-1}}$ was high which exhibited that this vector had much discriminatory power to differentiate the performance of genotypes under different salt concentrations (Fig. 1). In $\mathrm{Na}^{+} / \mathrm{K}^{+}$, two PCs $\left(\mathrm{PC}_{1}\right.$ and $\left.\mathrm{PC}_{2}\right)$ had eigen value more than one (Table 2). Contribution of $\mathrm{S}_{0.8 \mathrm{dsm}}{ }^{-}$ 1 and $\mathrm{S}_{4 \mathrm{dsm}^{-1}}$ were positive and negative in $\mathrm{PC}_{1}$ and $\mathrm{PC}_{2}$ respectively while the contribution of remaining environments was in opposite state in concerned PC (Table 2).

Analysis for root length under $\mathrm{S}_{0.8 \mathrm{dsm}}{ }^{-1}, \mathrm{~S}_{4 \mathrm{dsm}}{ }^{-1}, \mathrm{~S}_{6 \mathrm{dsm}}{ }^{-1}$ and $\mathrm{S}_{10}$ $\mathrm{dsm}^{-1}$ between $\mathrm{PC}_{1}$ and $\mathrm{PC}_{2}$ showed $80.68 \%$ interaction. Individually, $\mathrm{PC}_{1}$ and $\mathrm{PC}_{2}$ revealed 62.57 and $18.12 \%$ variation respectively. Genotypes UAC-0020, UAC-0024 and UAC-0036 scattered apart from the origin in positive direction between $\mathrm{S}_{0.8 \mathrm{dsm}}{ }^{-1}$ and $\mathrm{S}_{6 \mathrm{dsm}}{ }^{-1}$ environments with high mean grouped as highly variable and well adapted (Fig. 2). Genotypes UAC-0028, UAC-0033, UAC-0041 and UAC0048 positioned in negative quadrant and opposite sides of environment vectors showed comparative poor adaptability

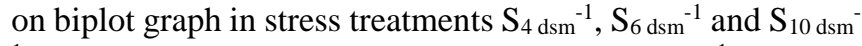
${ }^{1}$ when compared with control treatment $S_{0.8 ~ d s m}{ }^{-1}$ (Fig. 2). Spoke length of $\mathrm{S}_{10 \mathrm{dsm}^{-1}}$ vector was longest among all treatment vectors therefore proved as most interactive treatment for root length. $\mathrm{S}_{0.8 \mathrm{dsm}^{-1}}$ and $\mathrm{S}_{10 \mathrm{dsm}}{ }^{-1}$ environments had different interactive response with genotypes due to high angle within them while $\mathrm{S}_{4} \mathrm{dsm}^{-1}$ and $\mathrm{S}_{6 \mathrm{dsm}^{-1}}$ had similar interactive response as having small angle within them (Fig. 2). Only $\mathrm{PC}_{1}$ had remarkable eigen value which was more than two (Table 2). Contribution of all the environments

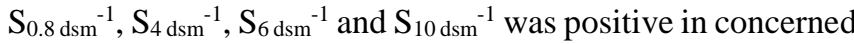
PC.

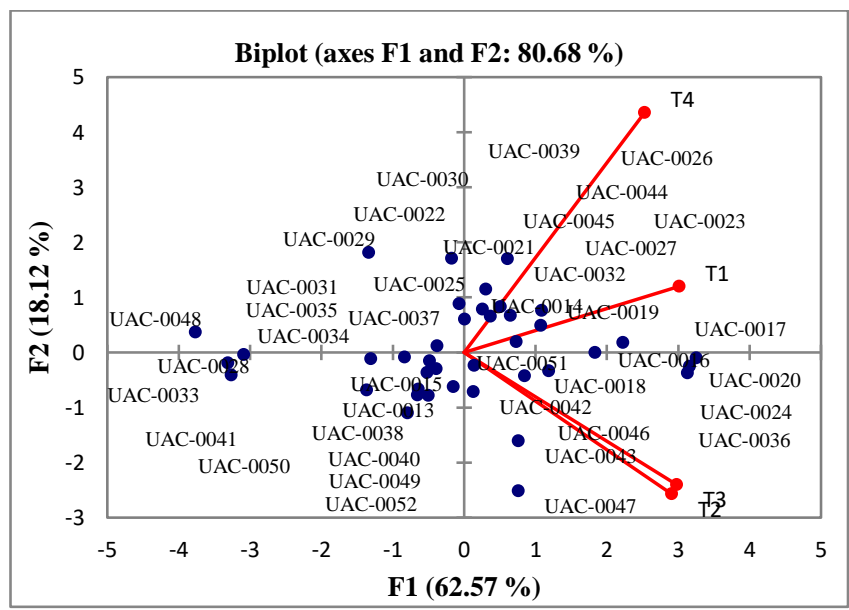

Figure 2. PCA Biplot for RL.

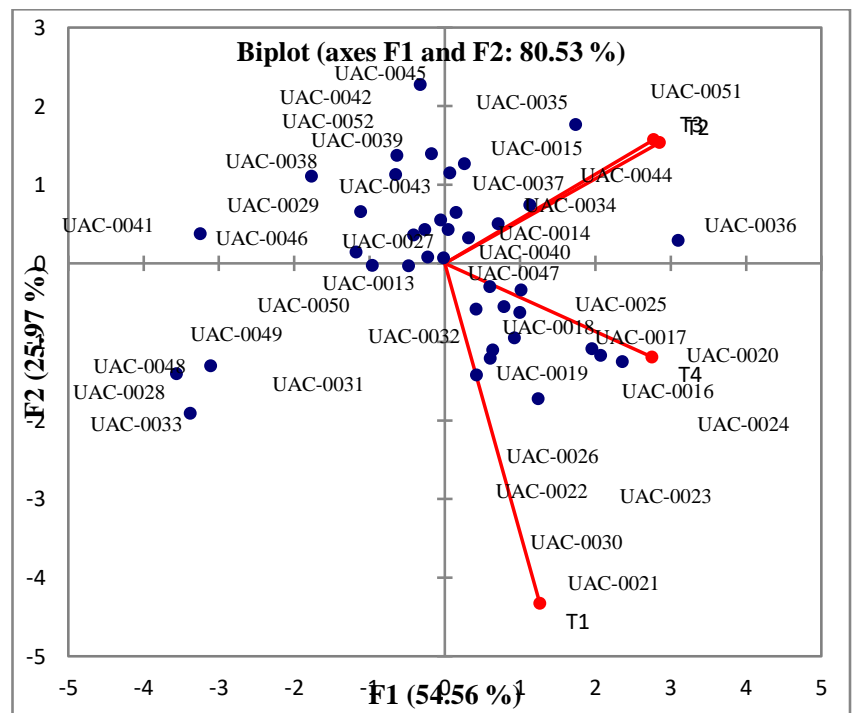

Figure 3. PCA Biplot for $\mathrm{K}^{+}$.

Biplot analysis for $\mathrm{K}^{+}$concentration exhibited $80.53 \%$ interaction between $\mathrm{PC}_{1}$ and $\mathrm{PC}_{2}$. Individually, $\mathrm{PC}_{1}$ and $\mathrm{PC}_{2}$ showed $54.56 \%$ and $25.97 \%$ variation respectively under $\mathrm{S}_{0.8}$ $\mathrm{dsm}^{-1}, \mathrm{~S}_{4 \mathrm{dsm}}{ }^{-1}, \mathrm{~S}_{6 \mathrm{dsm}}{ }^{-1}$ and $\mathrm{S}_{10 \mathrm{dsm}}{ }^{-1}$ (Fig. 3). There was a huge dispersion of genotypes on biplot graph for $\mathrm{K}^{+}$concentration which depicted variable response of genotypes with respect to saline environment (Fig. 3). UAC-0020, UAC-0024 and UAC-0036 scattered towards the positive value region termed as more variable and more adapted in saline condition (Fig. 3). UAC-0028, UAC-0033, UAC-0041 and UAC-0048 
Table 2. PC values, eigenvalues, percent variance and cumulative percent of variance for different traits under normal and stress conditions.

\begin{tabular}{|c|c|c|c|c|c|c|}
\hline \multirow[t]{2}{*}{ Traits/Environments } & $\mathbf{P C}_{1}$ & $\mathbf{P C}_{2}$ & $\mathbf{P C}(\mathbf{S})$ & Eigen values & $\%$ variance & Cumulative \% of variance \\
\hline & $\mathbf{T}_{1}$ & $\mathbf{T}_{1}$ & $\mathbf{T}_{1}$ & $\mathbf{T}_{1}$ & $\mathbf{T}_{1}$ & $\mathbf{T}_{1}$ \\
\hline SL & 0.72 & -0.50 & $\mathrm{PC}_{1}$ & 2.28 & 57.09 & 57.09 \\
\hline RL & 0.83 & - & $\mathrm{PC}_{1}$ & 2.50 & 62.57 & 62.57 \\
\hline SFW & 0.60 & - & $\mathrm{PC}_{1}$ & 2.24 & 56.00 & 56.00 \\
\hline SDW & 0.75 & - & $\mathrm{PC}_{1}$ & 2.14 & 53.54 & 53.54 \\
\hline RFW & 0.75 & - & $\mathrm{PC}_{1}$ & 2.36 & 59.19 & 59.19 \\
\hline RDW & 0.54 & - & $\mathrm{PC}_{1}$ & 2.04 & 50.95 & 50.95 \\
\hline $\mathrm{Na}^{+}$ & -0.10 & 0.96 & $\mathrm{PC}_{1}$ & 1.93 & 48.49 & 48.49 \\
\hline $\mathrm{Cl}^{-}$ & -0.20 & 0.90 & $\mathrm{PC}_{1}$ & 1.90 & 48.90 & 48.90 \\
\hline $\mathrm{K}^{+}$ & 0.37 & -0.80 & $\mathrm{PC}_{1}$ & 2.18 & 54.55 & 54.55 \\
\hline PRO & 0.62 & - & $\mathrm{PC}_{1}$ & 2.09 & 52.37 & 52.37 \\
\hline $\mathrm{Na}^{+} / \mathrm{K}^{+}$ & -0.10 & 0.99 & $\mathrm{PC}_{1}$ & 2.35 & 58.75 & 58.75 \\
\hline \multirow[t]{2}{*}{ Traits/Environment } & $\mathbf{P C}_{1}$ & $\mathbf{P C}_{2}$ & $\mathbf{P C}(\mathbf{S})$ & Eigen values & $\%$ variance & Cumulative $\%$ of variance \\
\hline & $\mathbf{T}_{2}$ & $\mathbf{T}_{2}$ & $\mathbf{T}_{2}$ & $\mathbf{T}_{2}$ & $\mathbf{T}_{2}$ & $\mathbf{T}_{2}$ \\
\hline SL & 0.80 & -0.40 & $\mathrm{PC}_{2}$ & 1.00 & 25.03 & 80.43 \\
\hline RL & 0.80 & - & $\mathrm{PC}_{2}$ & 0.72 & 18.12 & 80.68 \\
\hline SFW & 0.68 & - & $\mathrm{PC}_{2}$ & 0.83 & 20.95 & 76.95 \\
\hline SDW & 0.66 & - & $\mathrm{PC}_{2}$ & 0.72 & 17.93 & 71.47 \\
\hline RFW & 0.78 & - & $\mathrm{PC}_{2}$ & 0.56 & 14.24 & 73.43 \\
\hline RDW & 0.70 & - & $\mathrm{PC}_{2}$ & 0.83 & 20.66 & 71.61 \\
\hline $\mathrm{Na}^{+}$ & 0.73 & -0.20 & $\mathrm{PC}_{2}$ & 1.04 & 25.95 & 74.44 \\
\hline $\mathrm{Cl}^{-}$ & 0.75 & -0.20 & $\mathrm{PC}_{2}$ & 1.04 & 26.19 & 75.12 \\
\hline $\mathrm{K}^{+}$ & 0.84 & 0.31 & $\mathrm{PC}_{2}$ & 1.03 & 25.97 & 80.53 \\
\hline PRO & 0.75 & - & $\mathrm{PC}_{2}$ & 0.90 & 22.44 & 74.81 \\
\hline $\mathrm{Na}^{+} / \mathrm{K}^{+}$ & 1.00 & -0.10 & $\mathrm{PC}_{2}$ & 1.00 & 25.00 & 84.00 \\
\hline \multirow{2}{*}{ Traits/Environment } & $\mathbf{P C}_{1}$ & $\mathbf{P C}_{2}$ & $\mathbf{P C}(\mathbf{S})$ & Eigen values & $\%$ variance & Cumulative $\%$ of variance \\
\hline & $\mathbf{T}_{3}$ & $\mathbf{T}_{3}$ & $\mathbf{T}_{3}$ & $T_{3}$ & $\mathbf{T}_{3}$ & $\mathbf{T}_{3}$ \\
\hline SL & 0.85 & 0.25 & $\mathrm{PC}_{3}$ & 0.44 & 10.90 & 91.32 \\
\hline RL & 0.82 & - & $\mathrm{PC}_{3}$ & 0.42 & 10.56 & 91.24 \\
\hline SFW & 0.84 & - & $\mathrm{PC}_{3}$ & 0.55 & 13.75 & 90.70 \\
\hline SDW & 0.77 & - & $\mathrm{PC}_{3}$ & 0.59 & 14.78 & 86.25 \\
\hline RFW & 0.77 & - & $\mathrm{PC}_{3}$ & 0.54 & 13.72 & 87.15 \\
\hline RDW & 0.79 & - & $\mathrm{PC}_{3}$ & 0.67 & 16.71 & 88.33 \\
\hline $\mathrm{Na}^{+}$ & 0.86 & 0.19 & $\mathrm{PC}_{3}$ & 0.64 & 16.20 & 90.65 \\
\hline $\mathrm{Cl}^{-}$ & 0.80 & 0.35 & $\mathrm{PC}_{3}$ & 0.59 & 14.81 & 89.93 \\
\hline $\mathrm{K}^{+}$ & 0.82 & 0.32 & $\mathrm{PC}_{3}$ & 0.44 & 11.20 & 91.73 \\
\hline PRO & 0.88 & - & $\mathrm{PC}_{3}$ & 0.64 & 16.09 & 90.90 \\
\hline $\mathrm{Na}^{+} / \mathrm{K}^{+}$ & 0.92 & 0.10 & $\mathrm{PC}_{3}$ & 0.45 & 11.34 & 95.14 \\
\hline \multirow[t]{2}{*}{ Traits/Environment } & $\mathbf{P C}_{1}$ & $\mathbf{P C}_{2}$ & $\mathbf{P C}(\mathbf{S})$ & Eigen values & $\%$ variance & Cumulative $\%$ of variance \\
\hline & $\mathbf{T}_{4}$ & $\mathbf{T}_{4}$ & $\mathbf{T}_{4}$ & $\mathbf{T}_{4}$ & $\mathbf{T}_{4}$ & $\mathbf{T}_{4}$ \\
\hline SL & 0.64 & 0.69 & $\mathrm{PC}_{4}$ & 0.35 & 8.68 & 100 \\
\hline RL & 0.70 & - & $\mathrm{PC}_{4}$ & 0.35 & 8.76 & 100 \\
\hline SFW & 0.83 & - & $\mathrm{PC}_{4}$ & 0.37 & 9.29 & 100 \\
\hline SDW & 0.74 & - & $\mathrm{PC}_{4}$ & 0.55 & 13.75 & 100 \\
\hline RFW & 0.76 & - & $\mathrm{PC}_{4}$ & 0.51 & 12.84 & 100 \\
\hline RDW & 0.79 & - & $\mathrm{PC}_{4}$ & 0.47 & 11.67 & 100 \\
\hline $\mathrm{Na}^{+}$ & 0.80 & 0.12 & $\mathrm{PC}_{4}$ & 0.37 & 9.34 & 100 \\
\hline $\mathrm{Cl}^{-}$ & 0.83 & 0.09 & $\mathrm{PC}_{4}$ & 0.40 & 10.06 & 100 \\
\hline $\mathrm{K}^{+}$ & 0.81 & -0.20 & $\mathrm{PC}_{4}$ & 0.33 & 8.26 & 100 \\
\hline PRO & 0.61 & - & $\mathrm{PC}_{4}$ & 0.36 & 9.10 & 100 \\
\hline $\mathrm{Na}^{+} / \mathrm{K}^{+}$ & 0.89 & 0.04 & $\mathrm{PC}_{4}$ & 0.19 & 4.85 & 100 \\
\hline
\end{tabular}

separated in negative value region with low variability and low adaptability (Fig. 3). UAC-0041 was more dispersed and showed more variability than UAC-0028, UAC-0033 and UAC-0048 against saline environment (Fig. 3). Increased spoke length of $\mathrm{S}_{0.8 \mathrm{dsm}^{-1}}$ vector expressed that genotypes were more affected by $\mathrm{S}_{0.8 \mathrm{dsm}^{-1}}$ vector. UAC-0030 positioned exactly on spoke of $\mathrm{S}_{0.8} \mathrm{dsm}^{-1}$ with high affection with corresponding vector. Huge cosine angle between $\mathrm{S}_{0.8 \mathrm{dsm}^{-1}}$

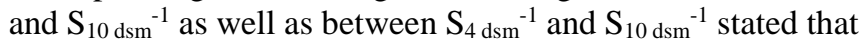
different genotypes attracted in different fashions towards $S_{0.8}$ $\mathrm{dsm}^{-1}$ and $\mathrm{S}_{10 \mathrm{dsm}^{-1}}$ similarly between $\mathrm{S}_{4} \mathrm{dsm}^{-1}$ and $\mathrm{S}_{10 \mathrm{dsm}^{-1}}$ vectors. Greater than 1 eigen value was shown by $\mathrm{PC}_{1}$ and 
$\mathrm{PC}_{2}$ (Table 2). The contributions of all the saline environments were positive in $\mathrm{PC}_{1}$ (Table 2). In $\mathrm{PC}_{2}$, two environments $\mathrm{S}_{0.8} \mathrm{dsm}^{-1}$ and $\mathrm{S}_{10} \mathrm{dsm}^{-1}$ were negatively contributing while $\mathrm{S}_{4} \mathrm{dsm}^{-1}$ and $\mathrm{S}_{6} \mathrm{dsm}^{-1}$ were positively contributing (Table 2).

$80.43 \%$ interaction between $\mathrm{PC}_{1}$ and $\mathrm{PC}_{2}$ was reported for shoot length under PCA biplot analysis where $\mathrm{PC}_{1}$ contributed $57.09 \%$ and $\mathrm{PC}_{2}$ contributed $23.33 \%$ variation. Vector lengths of $\mathrm{S}_{0.8 \mathrm{dsm}}{ }^{-1}$ and $\mathrm{S}_{4 \mathrm{dsm}^{-1}}$ were almost same which reflected that both vectors had equal discrimination powers for the explanation of 40 genotypes. Genotypes UAC-0020, UAC-0024 and UAC-0036 had high mean values of shoot length grouped as well adapted and best performing as secured position farther from origin in positive quadrant on

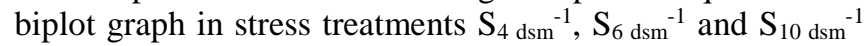
when compared with control treatment $\mathrm{S}_{0.8 \mathrm{dsm}^{-1}}$ (Fig. 4). Genotypes UAC-0028, UAC-0033, UAC-0041 and UAC0048 positioned in negative quadrant and opposite sides of environment vectors showed comparative poor adaptability

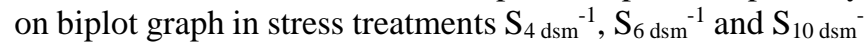
1 when compared with control treatment $\mathrm{S}_{0.8 \mathrm{dsm}^{-1}}$ (Fig. 4). Graph for shoot length showed that $\mathrm{S}_{6 \mathrm{dsm}^{-1}}$ and $\mathrm{S}_{10 \mathrm{dsm}}{ }^{-1}$ had longer spoke length and stronger interactive force followed by $\mathrm{S}_{0.8 \mathrm{dsm}^{-1}}$ and $\mathrm{S}_{4 \mathrm{dsm}}{ }^{-1}$ (Fig. 4). Two PCs $\left(\mathrm{PC}_{1}\right.$ and $\mathrm{PC}_{2}$ ) had eigen value greater than one (Table 2). In case of $\mathrm{PC}_{1}$, all environments showed positive contribution whereas in case

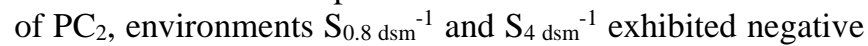
contribution while environments $S_{6 \mathrm{dsm}^{-1}}$ and $\mathrm{S}_{10 \mathrm{dsm}^{-1}}$ showed positive contribution (Table 2).

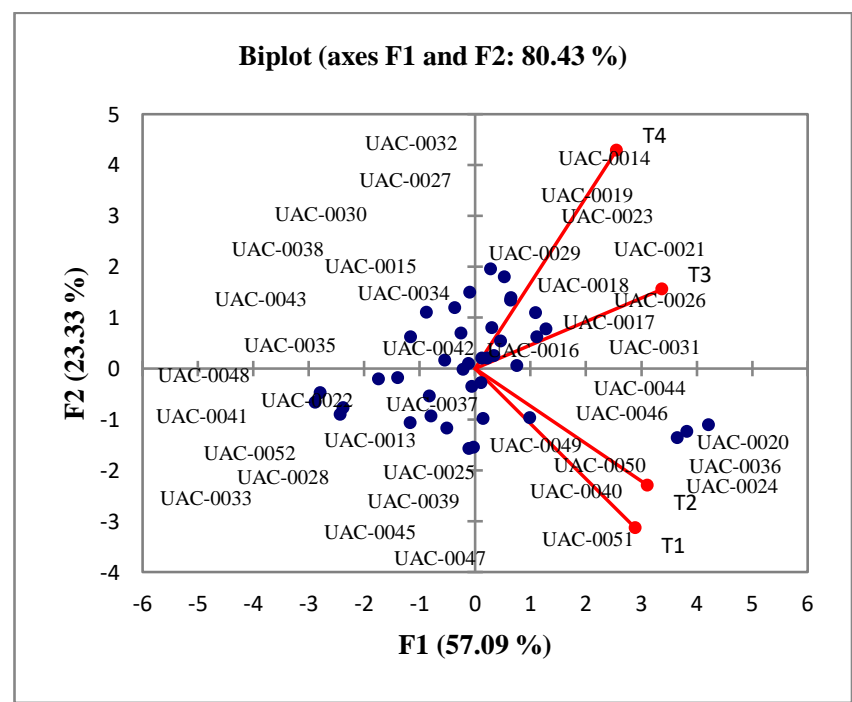

\section{Figure 4. PCA Biplot for SL.}

Biplot for shoot fresh weight was plotted among $\mathrm{PC}_{1}$ and $\mathrm{PC}_{2}$, $76.96 \%$ variation was elucidated by these two components in which $\mathrm{PC}_{1}$ depicted $56.01 \%$ and $\mathrm{PC}_{2}$ revealed $20.95 \%$ variation (Fig. 5). UAC-0020, UAC-0024 and UAC-0036 scattered in positive value region between $S_{0.8 \mathrm{dsm}^{-1}}$ and $\mathrm{S}_{6 \mathrm{dsm}}{ }^{-}$
1 and had high means showing high variability therefore grouped as well adapted (Fig. 5). UAC-0028, UAC-0033, UAC-0041 and UAC-0048 showed comparatively poor adaptability in $\mathrm{S}_{4 \mathrm{dsm}}{ }^{-1}, \mathrm{~S}_{6 \mathrm{dsm}}{ }^{-1}$ and $\mathrm{S}_{10 \mathrm{dsm}^{-1}}$ as compared to $\mathrm{S}_{0.8}$ $\mathrm{dsm}^{-1}$ (Fig. 5). All the environments had same interactive force for most of genotypes. $\mathrm{S}_{6 \mathrm{dsm}^{-1}}$ had strong positive interactive force with UAC-0016, UAC-0017 and UAC-0026 (Fig. 5). Different responses of genotypes to variable saline environments were confirmed by the large angle between $S_{0.8}$ $\mathrm{dsm}^{-1}, \mathrm{~S}_{4 \mathrm{dsm}}{ }^{-1}, \mathrm{~S}_{6 \mathrm{dsm}^{-1}}$ and $\mathrm{S}_{10 \mathrm{dsm}}{ }^{-1}$ (Fig. 5). As far as eigen value was concerned, only $\mathrm{PC}_{1}$ had worth mentioning value which was more than two (Table 2). All the saline environment

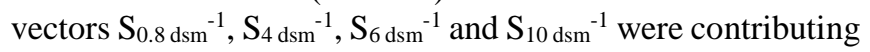
positively in that PC (Table 2).

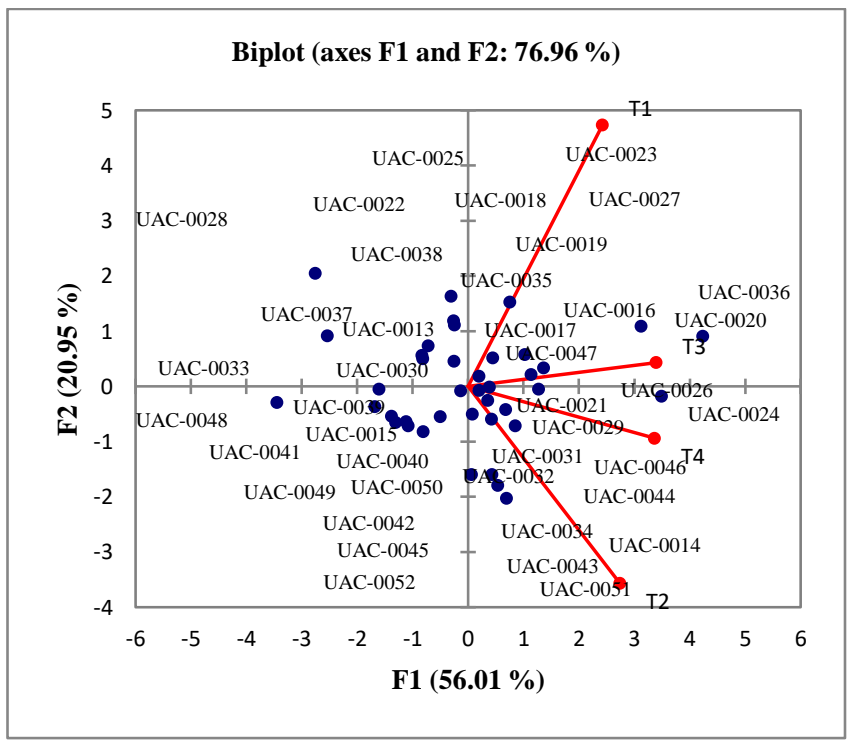

Figure 5. PCA Biplot for SFW.

Contribution of interaction representing $\mathrm{PC}_{1}$ and $\mathrm{PC}_{2}$ was $75.12 \%$ collectively in which $48.93 \%$ variation was observed by $\mathrm{PC}_{1}$ and $26.19 \%$ variation was observed by $\mathrm{PC}_{2}$ for

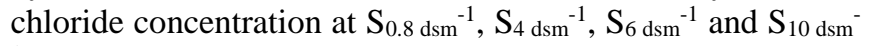
1. UAC-0028, UAC-0033, UAC-0041 and UAC-0048 were placed in positive value region of the graph while UAC-0020, UAC-0024 and UAC-0036 were dispersed in a negative value region of the graph (Fig. 6). UAC-0028, UAC-0041 and UAC-0048 were positioned in direction of $\mathrm{S}_{6 \mathrm{dsm}^{-1}}$ vector with high interaction (Fig. 6). UAC-0033 got place towards the head of $\mathrm{S}_{4} \mathrm{dsm}^{-1}$ vector showing that it had high positive relation with this vector. UAC-0031 and UAC-0049 fell exactly on the spokes of $\mathrm{S}_{6 \mathrm{dsm}^{-1}}$ and $\mathrm{S}_{10 \mathrm{dsm}^{-1}}$ respectively, which confirmed their strong positive interaction with concerned vectors (Fig. 6). $\mathrm{S}_{4} \mathrm{dsm}^{-1}$ and $\mathrm{S}_{10 \mathrm{dsm}^{-1}}$ were remarkably huge in spoke length, which indicated different responses for genotypes regarding salinity. The angle between vectors $S_{6} \mathrm{dsm}^{-1}$ and $\mathrm{S}_{10 \mathrm{dsm}^{-1}}$ proved that genotypes were responding in different manner against salinity (Fig. 6). 
$\mathrm{PC}_{1}$ and $\mathrm{PC}_{2}$ contained eigen value more than one (Table 2). $\mathrm{S}_{0.8 \mathrm{dsm}^{-1}}$ and $\mathrm{S}_{4} \mathrm{dsm}^{-1}$ were contributing positively and negatively in $\mathrm{PC}_{1}$ and $\mathrm{PC}_{2}$ respectively while the contribution of remaining environments was in an opposite state in concerned PC (Table 2).

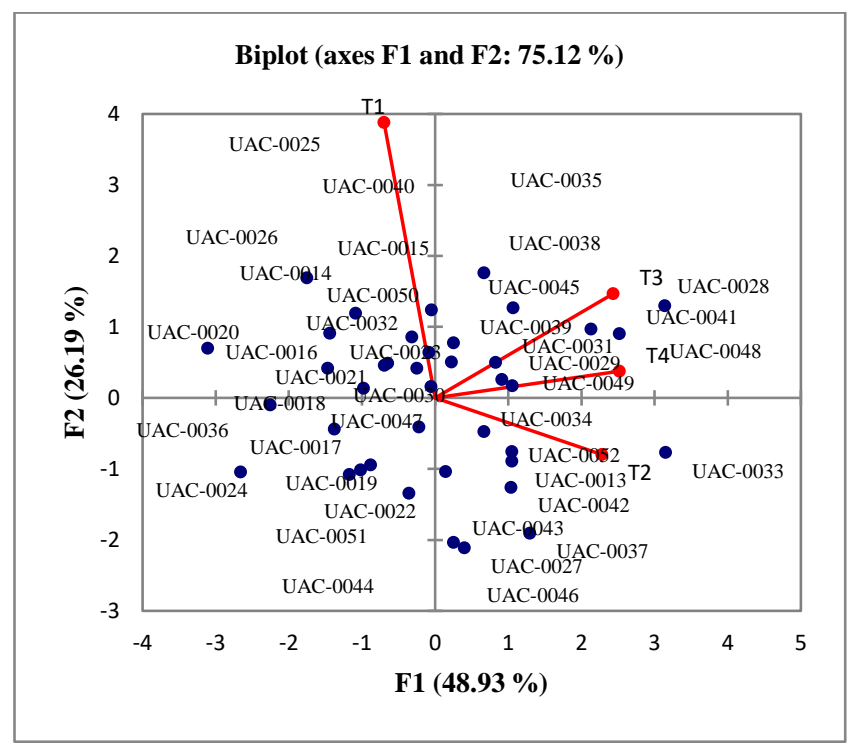

Figure 6. PCA Biplot for $\mathrm{Cl}^{-}$.

PCA biplot for proline contents under four environments revealed $74.81 \%$ interaction (Fig. 7). High variation (52.37\%) reported by $\mathrm{PC}_{1}$ while $\mathrm{PC}_{2}$ showed $22.44 \%$ variation. UAC0028, UAC-0033, UAC-0041 and UAC-0048 located far away from origin of graph in negative direction opposite to environment vectors proving low variability and adaptability. UAC-0020, UAC-0024 and UAC-0036 scattered apart from origin towards the heads of vectors in positive direction of graph with excellent variability and adaptability (Fig. 7). UAC-0028, UAC-0033, UAC-0041 and UAC-0048 performed differently with disperse position on graph in context of response to salinity vectors individually (Fig. 7). Angle of $\mathrm{S}_{6 \mathrm{dsm}}{ }^{-1}$ with $\mathrm{S}_{10 \mathrm{dsm}}{ }^{-1}$ was large which depicted that genotypes responded in different fashion with these vectors. Spoke length of $\mathrm{S}_{6 \mathrm{dsm}^{-1}}$ was little bit high as compared to all other environments which prove its high interaction with genotypes than other three vectors. In case of proline contents, there was only $\mathrm{PC}_{1}$ which contained eigen value more than two (Table 2). Positive contribution of all the environments

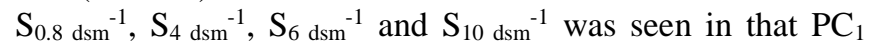
(Table 2).

PCA biplot for sodium concentration under four environments revealed $74.45 \%$ interaction of $\mathrm{PC}_{1}$ and $\mathrm{PC}_{2}$ for variation while their separate contribution was $48.49 \%$ and $25.95 \%$ respectively; whole set of genotypes were distantly separated on biplot graph (Fig. 8) which explained that all genotypes were sensitive to variable saline environments. UAC-0020, UAC-0024 and UAC-0036 positioned in negative value region while UAC-0028, UAC-0033, UAC0041 and UAC-0048 positioned in positive value region (Fig. 8).

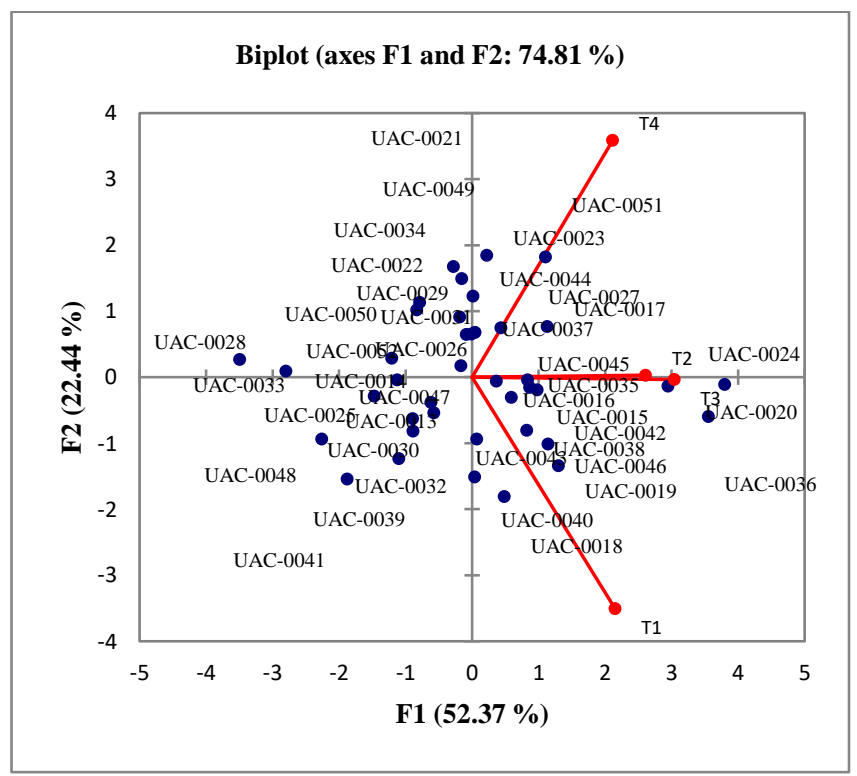

Figure 7. PCA Biplot for PRO.

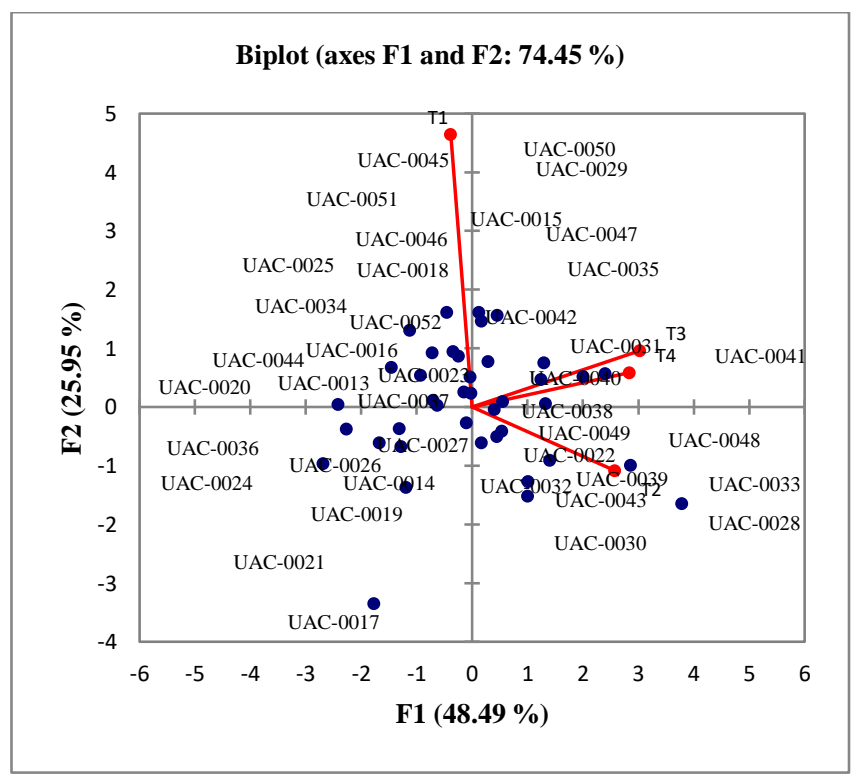

Figure 8. PCA Biplot for $\mathrm{Na}^{+}$.

The spoke angle was very large between $\mathrm{S}_{4 \mathrm{dsm}^{-1}}$ and $\mathrm{S}_{10 \mathrm{dsm}}{ }^{-1}$ and very small between $S_{6} \mathrm{dsm}^{-1}$ and $S_{10 ~ d s m}{ }^{-1}$ narrating that genotypes interacted differently with $\mathrm{S}_{4} \mathrm{dsm}^{-1}$ and $\mathrm{S}_{10} \mathrm{dsm}^{-1}$ rather than $\mathrm{S}_{6 \mathrm{dsm}}{ }^{-1}$ and $\mathrm{S}_{10 \mathrm{dsm}^{-1}}$ (Fig. 8). UAC-0039 and UAC0049 were placed along the spoke length of $\mathrm{S}_{4} \mathrm{dsm}^{-1}$ which indicated that it had positive strong interactive force with corresponding vector. $\mathrm{S}_{0.8 \mathrm{dsm}^{-1}}$ and $\mathrm{S}_{6} \mathrm{dsm}^{-1}$ vectors had different interaction with genotypes which was confirmed by 
the large angle between corresponding environment vectors. Two PCs ( $\mathrm{PC}_{1}$ and $\mathrm{PC}_{2}$ ) showed eigen value greater than one thus retained for further studies (Table 2). In $\mathrm{PC}_{1}$ all environments were positively contributing except $\mathrm{S}_{0.8} \mathrm{dsm}^{-1}$ while in $\mathrm{PC}_{2}$ all environments were performing positively except $\mathrm{S}_{4 \mathrm{dsm}^{-1}}$ (Table 2).

Biplot for root fresh weight under four salinity environments plotted between $\mathrm{PC}_{1}$ and $\mathrm{PC}_{2}$ showed $73.44 \%$ of total interaction in which share of $\mathrm{PC}_{1}$ and $\mathrm{PC}_{2}$ was $59.20 \%$ and $14.24 \%$ respectively (Fig. 9). UAC-0020, UAC-0024 and UAC-0036 were reported as tolerant with high variability and more adapted to saline environments due to their scattering in positive value region (Fig. 9). UAC-0028, UAC-0033, UAC0041 and UAC-0048 scattered in negative value region showing poor response for variability and adaptability to environment vectors (Fig. 9). Vector $\mathrm{S}_{6 \mathrm{dsm}^{-1}}$ was showing unexpected response towards genotypes. It had small spoke length which explained that its interactive force was very low towards genotypes. $\mathrm{S}_{0.8 \mathrm{dsm}^{-1}}$ vector had high spoke length showing high interactive force towards genotypes in terms of environmental effect (Fig. 9). The genotype UAC-0016 positioned along with $\mathrm{S}_{6} \mathrm{dsm}^{-1}$ proved its affinity towards this salinity vector (Fig. 9). Again $\mathrm{PC}_{1}$ carried eigen value more than two (Table 2). Positive contribution of all the environments $\mathrm{S}_{0.8 \mathrm{dsm}}{ }^{-1}, \mathrm{~S}_{4 \mathrm{dsm}}{ }^{-1}, \mathrm{~S}_{6 \mathrm{dsm}}{ }^{-1}$ and $\mathrm{S}_{10 \mathrm{dsm}}{ }^{-1}$ were seen in $\mathrm{PC}_{1}$ and $\mathrm{PC}_{2}$ (Table 2).

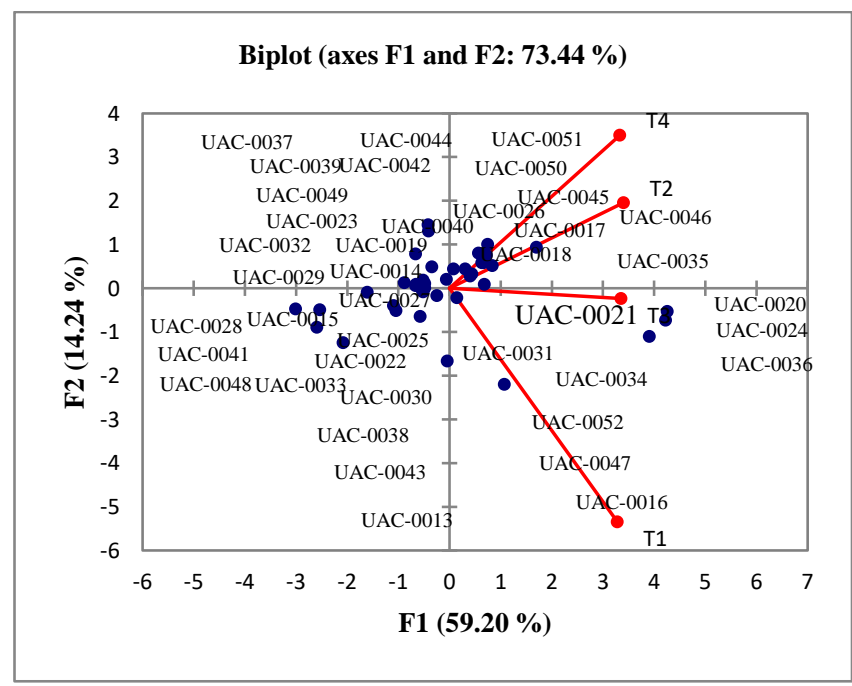

Figure 9. PCA Biplot for RFW.

In Figure 10, biplot analysis exhibited $71.61 \%$ interaction between $\mathrm{PC}_{1}$ and $\mathrm{PC}_{2}$, where individual contribution of these components toward variation was $50.95 \%$ and $20.66 \%$

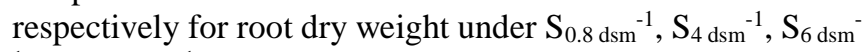
${ }^{1}$ and $S_{10 \mathrm{dsm}^{-1}}$. There was less dispersion of genotypes seen in this biplot graph against different salinity vectors (Fig. 10). UAC-0020, UAC-0024 and UAC-0036 depicted interesting response with increased scattering individually in positive side towards salinity vectors on biplot graph (Fig. 10). Similarly, UAC-0041 and UAC-0048 also scattered distantly opposite to salinity vectors but UAC-0028 and UAC-0033 shared same position in negative region opposite to

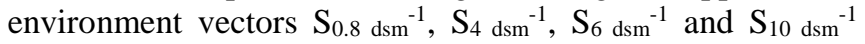
(Fig. 10). Rest of the genotypes dispersed in-between the negative and positive regions of graph with varied variability and adaptability. Very high spoke length and very high angle of $\mathrm{S}_{0.8 \mathrm{dsm}}{ }^{-1}$ with rest of environment vectors explained that $\mathrm{S}_{0.8}$ $\mathrm{dsm}^{-1}$ had high interactive force and different interactive response for genotypes. Only $\mathrm{PC}_{1}$ showed greater than two eigen value (Table 2). Positive contribution was noticed by

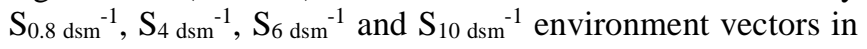
concerned PC.

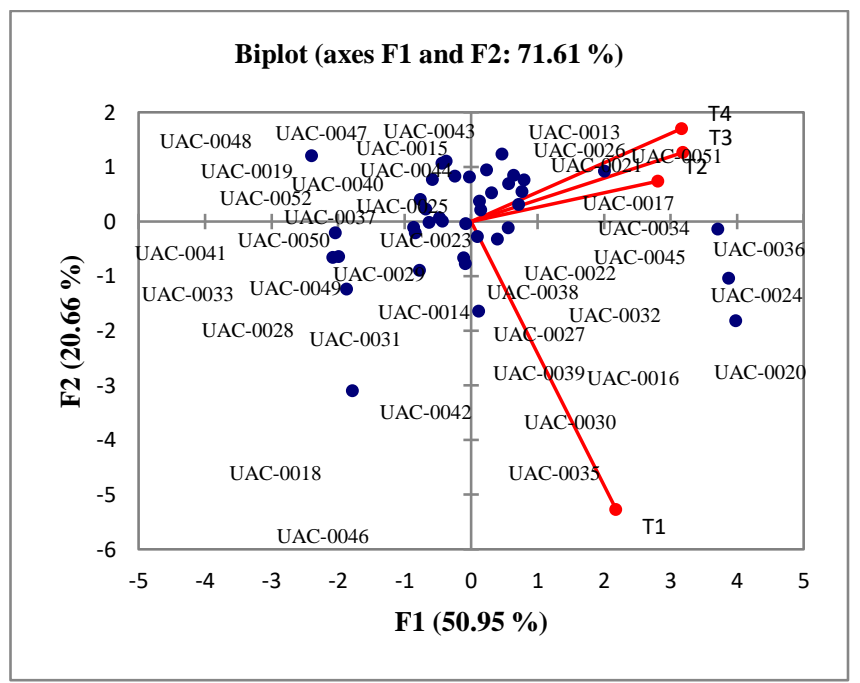

Figure 10. PCA Biplot for RDW.

Contribution of interaction representing $\mathrm{PC}_{1}$ and $\mathrm{PC}_{2}$ was $71.47 \%$ for shoot dry weight at salinity levels $\mathrm{S}_{0.8 \mathrm{dsm}}{ }^{-1}, \mathrm{~S}_{4 \mathrm{dsm}}$ ${ }^{1}, \mathrm{~S}_{6 \mathrm{dsm}^{-1}}$ and $\mathrm{S}_{10 \mathrm{dsm}^{-1}}$ in which contribution of $\mathrm{PC}_{1}$ and $\mathrm{PC}_{2}$ was $53.54 \%$ and $17.93 \%$ respectively (Fig. 11). The entire genotypes showed well scattered pattern on biplot graph which confirmed that all genotypes had strong response towards saline environments. All the vectors of environment also had large angle with each other which showed that these vectors differed with each other in interactive response with genotypes. UAC-0020, UAC-0024 and UAC-0036 fell in positive region apart from the origin of graph towards $S_{0.8 \mathrm{dsm}}$ 1 vector with high mean, good variability and adaptability (Fig. 11). UAC-0028, UAC-0033, UAC-0041 and UAC-0048 were consistent in their response to saline environment on biplot graph showed susceptibility, poor variability and poor adaptability by falling in negative direction opposite to the environment vectors due to their less mean values (Fig. 11). Observed eigen value was more than two in $\mathrm{PC}_{1}$. Contribution of all the environment vectors was positive (Table 2). 


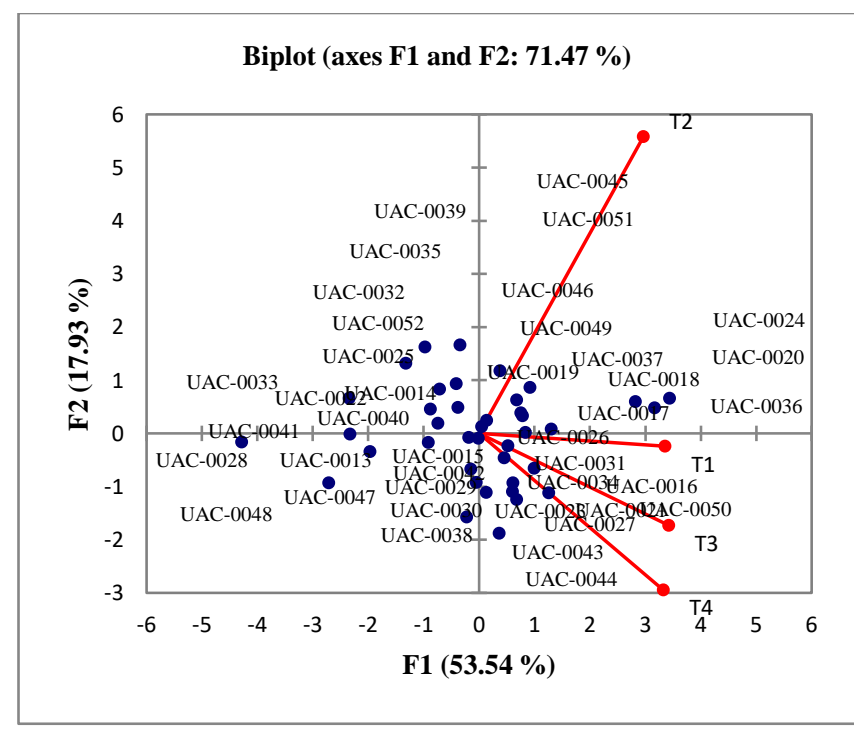

Figure 11. PCA Biplot for SDW.

Consequently UAC-0020 and UAC-0024 performed well

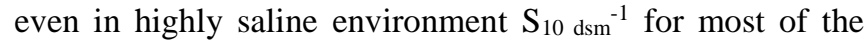
traits while UAC-0036 performed well only for trait $\mathrm{Na}^{+} / \mathrm{K}^{+}$ ratio. UAC-0028 performed poor even in least saline environment $\mathrm{S}_{4} \mathrm{dsm}^{-1}$ regarding most of the traits whereas UAC-0048 performed poor only for root fresh weight.

\section{DISCUSSION}

Globally, the crop production is badly impacted by Biotic and abiotic stresses (Aslam et al., 2014). Germplasm is evaluated by different techniques but most reliable one is multivariate analyses. PCA which is widely applicable is unsupervised (without response variable/dependent variable) multivariate analysis can be used efficiently for germplasm evaluation. The major concern to use PCA is to reduce dimensionality and to achieve parsimony to retrieve the least possible number of components which governs original variation of original multivariate data. Maximum variation in data explained by first principal components is indication of successfully achieved objectives of PCA. In our findings, $\mathrm{PC}_{1}$ and $\mathrm{PC}_{2}$ explained 80.43, 80.68, 76.96, 73.44, 71.47, 71.61, 74.45, $80.53,75.12,74.81$ and $83.80 \%$ cumulative variation for shoot length, root length, shoot fresh weight, root fresh weight, shoot dry weight, root dry weight, $\mathrm{Na}^{+}$concentration, $\mathrm{K}^{+}$concentration, $\mathrm{Cl}^{-}$concentration, proline contents and $\mathrm{Na}^{+} / \mathrm{K}^{+}$ratio respectively which showed that PCA was appropriate for this data and biplot on the basis of this data explained most of variation.

High degree of correlation among multiple variables is very useful for making the PCA very effective analysis. Shoot length, shoot dry weight, root fresh weight, $\mathrm{Na}^{+}$ concentration, $\mathrm{Cl}^{-}$concentration and proline contents had strong positive correlation with each other under all the four salinity treatments. Eigen value is very important criterion for selection of principle factors. It is cut off value which helps to decide which component should be retain for further study. In this study, two components $\left(\mathrm{PC}_{1}\right.$ and $\mathrm{PC}_{2}$ ) have eigen value greater than one for different environments and only these components are duly important for corresponding traits. Under $\mathrm{NaCl}$ stress, osmotic balance may have disturbed with increased concentration of external $\mathrm{Na}^{+}$and $\mathrm{Cl}^{-}$accordingly stimulating the water deficit. The salt injury ultimately the result of high $\mathrm{Na}^{+}$concentration in leaves due to toxic effect (Serrano et al., 1999). The different genotypes were reported with varied response within a treatment. Different treatment effects also proved variability in genotypes. Varietal comparison disclosed that poor performance in terms of growth was observed in genotypes having high $\mathrm{Na}^{+}$ concentration in their leaves.

Decreased $\mathrm{Na}^{+} / \mathrm{K}^{+}$ratio was shown by UAC-0024 and UAC0036 under $\mathrm{S}_{6 \mathrm{dsm}^{-1}}$ and $\mathrm{S}_{10 \mathrm{dsm}^{-1}}$. UAC-0028, UAC-0033 and UAC-0048 were noticed with increased $\mathrm{Na}^{+} / \mathrm{K}^{+}$ratio in $\mathrm{S}_{4} \mathrm{dsm}^{-}$

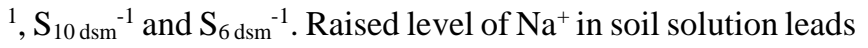
to reduce uptake of $\mathrm{K}^{+}$in plants as well as water, essential nutrients $(\mathrm{P}, \mathrm{K}, \mathrm{Fe}, \mathrm{Cu}$, and $\mathrm{Zn})$ and soil bacteria consequently increases $\mathrm{Na}^{+} / \mathrm{K}^{+}$ratio (Barea et al., 2005). Presently the tolerant genotypes UAC0024 and UAC0036 were expressing the least $\mathrm{Na}^{+} / \mathrm{K}^{+}$ratio due to high $\mathrm{K}^{+}$uptake while susceptible genotypes were showing increased $\mathrm{Na}^{+} / \mathrm{K}^{+}$ratio due to reduction in uptake of $\mathrm{K}^{+}$. Increased $\mathrm{Na}^{+} / \mathrm{K}^{+}$ratio badly impacts growth of plants. Disruption of various metabolic processes such as protein synthesis in the cytoplasm and ultimately plant growth by high $\mathrm{Na}^{+} / \mathrm{K}^{+}$ratio was also noticed by Tester and Davenport (2003).

Salt stress has considerable effect on root length (Gulzar et al., 2003). In current study root was severely affected due to salinity like UAC-0041 and UAC-0048 were reported with minimum root length in $\mathrm{S}_{10 \mathrm{dsm}^{-1}}$ and $\mathrm{S}_{6} \mathrm{dsm}^{-1}$ respectively whereas in no salt $\left(\mathrm{S}_{\left.0.8 \mathrm{dsm}^{-1}\right)}\right.$ UAC-0020 and UAC-0024 showed increased root length (Table 2). It is reported that root growth is sensitive to high salt concentrations and rapidly reduced by salinity (Ashraf et al., 2005). Similar results were observed in pearl millet by Hussain et al. (2008).

This study showed that $\mathrm{K}^{+}$concentration in UAC-0024 and UAC-0036 was high in least saline environment while reduced $\mathrm{K}^{+}$concentration was reported in UAC-0041 and UAC-0033 in high saline treatment. Reduction of $\mathrm{K}^{+}$ concentration was due to ion cytotoxicity stimulated by the translocation of $\mathrm{K}^{+}$with $\mathrm{Na}^{+}$. The decreased $\mathrm{K}^{+}$uptake is due to $\mathrm{Na}^{+}$uptakes through same $\mathrm{Na}^{+}-\mathrm{K}^{+}$co-transporters (Tammam et al., 2008). The reduction in uptake of $\mathrm{K}^{+}, \mathrm{Ca}^{+2}$, and $\mathrm{Mn}^{+2}$ was result of Ionic imbalance in the cells (Karimi et al., 2005). The $\mathrm{K}^{+}$plays vital role for osmoregulation, protein synthesis, to maintain cell turgor and stimulating photosynthesis (Ashraf, 2004). The integrity and function of cell membranes were maintained by $\mathrm{K}^{+}$and $\mathrm{Ca}^{+2}$ (Wenxue et al., 2003). 
Significant differences were observed among genotypes and $\mathrm{NaCl}$ concentration with respect to shoot length and root length. No salt or less salinity concentration in culture medium significantly enhanced shoot length but this may vary with plant species or genotype. In present study, high shoot

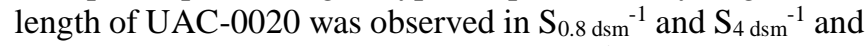

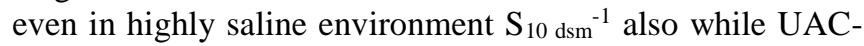
0036 showed worth mentioning increase in shoot length under salinity $\mathrm{S}_{6 \mathrm{dsm}}{ }^{-1}$ (Table 2). Pessarakli and Kopec (2009) found that shoot length decreased by the increasing salt concentrations. In our study, shoot length of UAC-0028 was decreased in $\mathrm{S}_{0.8 \mathrm{dsm}^{-1}}$, shoot length of UAC-0041 was reduced in $\mathrm{S}_{0.8 \mathrm{dsm}^{-1}}$ and $\mathrm{S}_{10 \mathrm{dsm}^{-1}}$ while least shoot length of UAC-0048 was noticed in $\mathrm{S}_{4} \mathrm{dsm}^{-1}$ and $\mathrm{S}_{6} \mathrm{dsm}^{-1}$ salinity levels. Similar results were reported by Mohammad et al. (1998) in tomato and by Gill and Singh (1989) in rice. The reduction in shoot length is due to excessive accumulation of salts in the cell wall elasticity. Further, secondary cells appear sooner and wall becomes rigid therefore the turgor pressure efficiency in cell enlargement decreases.

Less shoot fresh weight was due to higher accretion of $\mathrm{Na}^{+}$in leaves with least $\mathrm{K}^{+}$concentration and $\mathrm{K}^{+}: \mathrm{Na}^{+}$. Under saline environment, the prime cause of decline in plant growth seemed either due to osmotic drop in water availability or too much accretion of ions (Chinnusamy et al., 2005). The metabolic imbalances, fundamental alterations and disturbance in functions of proteins were consequents of ion cytotoxicity which was prompted by the transposition of $\mathrm{K}^{+}$ by $\mathrm{N}^{+}$in biochemical reactions as $\mathrm{Na}^{+}$ions pierced the hydration shells and affected the non-covalent interactions among their amino acids. A drop in the rates of net photosynthesis happens due to contrary effects on $\mathrm{CO}_{2}$ assimilation, which cause diminution in nutrient uptake and ultimately cause decline in growth of plants (Cha-Um and Kirdmanee, 2009). In our study, minimum shoot fresh weight was observed in case of UAC-0028 and UAC-0048 at highest salinity levels $\mathrm{S}_{10 \mathrm{dsm}^{-1}}$ and $\mathrm{S}_{6} \mathrm{dsm}^{-1}$ respectively, while maximum shoot fresh weight was observed in UAC-0036 under $\mathrm{S}_{4 \mathrm{dsm}}{ }^{-1}$ saline environment.

The tolerant genotype UAC-0020 had lowest $\mathrm{Cl}^{-}$ concentration under $\mathrm{S}_{4} \mathrm{dsm}^{-1}$ and $\mathrm{S}_{6 \mathrm{dsm}^{-1}}$ salinity levels and susceptible genotypes UAC-0028 and UAC-0033 had high $\mathrm{Cl}^{-}$concentration under $\mathrm{S}_{6} \mathrm{dsm}^{-1}$ and $\mathrm{S}_{10 \mathrm{dsm}^{-1}}$ respectively. Higher concentrations of external $\mathrm{Cl}^{-}$during $\mathrm{NaCl}$ stress might have disturbed the osmotic balance consequently inducing effect of water deficit. Salt injury was reported due to toxicity of leaves with increased concentrations of $\mathrm{Cl}^{-}$ (Serrano et al., 1999). Salt injury of plant leaves and stems is resultant of maximum inflow of $\mathrm{Cl}^{-}$associated with drop of $\mathrm{K}^{+}$uptake (Sharma, 1995).

Accumulation of solutes especially proline, glycine-betaine and sugars is a common observation under stress condition (Qasim et al., 2003). Leaf proline content in salt stressed plants increased as observed in maize by Carpici et al. (2010) and Moussa (2006). Proline accumulation in salt stressed plants is a primary defense response to maintain the osmotic pressure in a cell. It is also reported by Ashraf et al. (1998) that proline is an important osmolyte to adjust the plant under drought/saline conditions. Several other reports also show a significant role of proline in osmotic adjustment, protecting cell structure and its function in plants in salt-tolerant and saltsensitive cultivars of many crops (Desingh and Kanagaraj, 2007; Koca et al., 2007; Veeranagamallaiah et al., 2007; Turan et al., 2007a). The present study remained in accordance with the results of other researchers that the high salt treatments $\mathrm{S}_{10 \mathrm{dsm}}{ }^{-1}, \mathrm{~S}_{6 \mathrm{dsm}}{ }^{-1}$ and $\mathrm{S}_{4 \mathrm{dsm}}{ }^{-1}$ induced an increase in proline concentration in UAC-0020, UAC-0036 and UAC0024 maize genotypes (Table 2). Similar results have been reported by Cha-Um and Kirdmanee (2009) and Ashraf and Foolad (2005).

High concentration of Sodium in plant tissues reduced growth significantly, same results were observed in our study in which leaf sap of salt susceptible genotypes UAC-0028 in $\mathrm{S}_{4}$ $\mathrm{dsm}^{-1}$ and UAC-0048 in $\mathrm{S}_{6 \mathrm{dsm}^{-1}}$ and $\mathrm{S}_{10 \mathrm{dsm}^{-1} \text { contained }}$ maximum $\mathrm{Na}^{+}$concentration and created less dry matter. In contrast, elevation of production of shoot fresh weight was found in case of genotypes UAC-0020 and UAC-0024 as these genotypes were least with respect to $\mathrm{Na}^{+}$concentration in leaf. The toxicity in leaves enhanced due to high $\mathrm{Na}^{+}$ concentration which lead to severe salt injury. Our findings were in accordance with Munns et al. (2006) who wrote that least $\mathrm{Na}^{+}$concentration in shoot correlate with salt tolerance in wheat. Increasing levels of $\mathrm{NaCl}$ induced a progressive absorption of $\mathrm{Na}^{+}$and $\mathrm{Cl}^{-}$in plant, agreeing with Chavan and Karadge (1986). Excessive $\mathrm{Na}^{+}$concentration in the plant tissue hinders nutrient balance, osmotic regulation and causes toxicity (Bernstein, 1963). It is evident from the literature that plant tolerance to salinity is linked to lower $\mathrm{Na}^{+}$uptake and a subsequent reduced $\mathrm{Na}^{+}$accumulation protects leaf tissues (Tester and Davenport, 2003; Flowers, 2004; Munns and Tester, 2008).

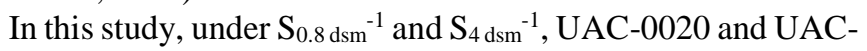
0024 showed a high root fresh weight. Due to high salt concentration in $\mathrm{S}_{6 \mathrm{dsm}^{-1}}$ and $\mathrm{S}_{4} \mathrm{dsm}^{-1}$, UAC-0041 and UAC0048 were depicted with least root fresh weight. The findings of our study agreed with some other researchers who claimed that fresh weight of root was one of the most adversely affected characters with increased salt stress level (Hameed $e t$ al., 2008). With the increase in salinity concentration there was a significant decrease in biomass production along with root fresh weight in black seeds (Hussain et al., 2009). Higher amount of sodium in plant tissues decreased growth significantly, which was reported in our findings like UAC0028 in $\mathrm{S}_{4} \mathrm{dsm}^{-1}$ and UAC-0048 in $\mathrm{S}_{6} \mathrm{dsm}^{-1}$ and $\mathrm{S}_{10 \mathrm{dsm}}{ }^{-1}$ contained maximum $\mathrm{Na}^{+}$concentration and produced dry matter in less amount, characteristics of salinity susceptible genotypes. In contrast, the genotypes UAC-0020 and UAC0024 had a lower $\mathrm{Na}^{+}$concentration and produced high shoot 
fresh weight. The $\mathrm{Na}^{+}$with high concentration in leaves become poisonous and lead to saline injury. In case of wheat, the salt tolerance was linked with low concentration of $\mathrm{Na}^{+}$in shoot (Munns et al., 2006). High $\mathrm{NaCl}$ concentration brought a progressive absorption of sodium and chloride ions in plant, supportive with Turan et al. (2007). Increased amount of $\mathrm{Na}^{+}$ ions in the plant tissue hampers nutrient balance, osmotic regulation and causes toxicity (Bernstein, 1963). It is evident from the review of literature that salinity tolerance of plant is associated with lower $\mathrm{Na}^{+}$concentration and that protects leaf tissues (Munns and Tester, 2008).

In this experiment, dry weight of root was significantly inhibited by salt (Table 2). The highest root dry weight was gained by tolerant genotypes UAC-0020, UAC-0024 and

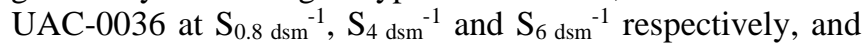
the lowest root dry weight was observed in sensitive genotypes UAC-0041 and UAC-0028 at the highest salinity level $\mathrm{S}_{10 \mathrm{dsm}^{-1}}$ and $\mathrm{S}_{4 \mathrm{dsm}^{-1}}$ respectively. Akram et al. (2007) reported that root dry weight of all corn hybrids showed a decline towards increase in salinity level.

Due to varied selectivity response for $\mathrm{K}^{+}$over $\mathrm{Na}^{+}$, different genotypes contained different extent of reduction in dry matter production (Ashraf, 2002). The significant decline in plant growth and dry-matter accretion in saline environments has been observed in many important legumes (Tejera et al., 2006). In our study least shoot dry weight was observed in case of UAC-0028 and UAC-0048 in $\mathrm{S}_{10 \mathrm{dsm}^{-1}}$ and $\mathrm{S}_{6 \mathrm{dsm}^{-1}}$ respectively whereas High shoot dry weight was seen in the case of UAC-0024 and UAC-0036 in low salinity levels i.e. $\mathrm{S}_{4 \mathrm{dsm}^{-1}}$ and $\mathrm{S}_{0.8 \mathrm{dsm}^{-1}}$ (Table 2). Our results are in agreement with the results of other researchers. For example, Hussain et al. (2007) reported that a negative relationship was detected between vegetative growth parameters and increasing salt concentration.

Conclusion: Different traits interact with environments differently. Shoot fresh weight, $\mathrm{Na}^{+}$concentration, $\mathrm{Cl}^{-}$ concentration, $\mathrm{K}^{+}$concentration and $\mathrm{Na}^{+} / \mathrm{K}^{+}$were verified as very good indicators of salinity tolerance. Performance of UAC-0020, UAC-0024 and UAC-0036 genotypes was good, even in highly saline environment, while UAC-0033, UAC0041 and UAC-0048 were poor, even in less saline environment. Biplot analysis is reported as an effective technique for exploitation of GEI. Evaluation of these genotypes remained purposeful to provide raw material for further breeding program to improve maize against salinity.

Acknowledgement: Financial grant under Ph.D. Indigenous Fellowship Program from higher education commission (HEC) Pakistan is greatly acknowledged by first author to conduct this study.

\section{REFERENCES}

Akram, M., A.M. Malik, M.Y. Ashraf, M.F. Saleem and M. Hussain. 2007. Competitive seedling growth and $\mathrm{K}^{+} / \mathrm{Na}^{+}$ ratio in different maize (Zea mays L.) hybrids under salinity stress. Pak. J. Bot. 39:2553-2563.

Akram, M., M.Y. Ashraf, R. Ahmad, E.A. Waraich, J. Iqbal and M. Mohsan. 2010. Screening for salt tolerance in maize (Zea mays L.) hybrids at an early seedling stage. Pak. J. Bot. 42:141-154.

Arzani, A. 2008. Improving salinity tolerance in crop plants: a biotechnological view. In Vitro Cell Dev. Biol. Plant. 44:373-383.

Ashraf, M. 1994. Breeding for salinity tolerance in plants. Crit. Rev. Plant Sci. 13:17-42.

Ashraf, M. 2002. Salt tolerance of cotton: some new advances. Crit. Rev. Plant Sci. 21:1-30.

Ashraf, M. 2004. Some important physiological selection criteria for salt tolerance in plants. Flora. 199:361-376.

Ashraf, M. and M.R. Foolad. 2005. Pre-sowing seed treatment-a shotgun approach to improve germination, plant growth, and crop yield under saline and nonsaline conditions. Adv. Agron. 88:223-271.

Ashraf, M.Y., K. Akhtar, G. Sarwar and M. Ashraf. 2005. Role of rooting system in salt tolerance potential of different guar accessions. Agron. Sustain. Dev. 25:243249.

Ashraf, M.Y., Y. Ali and T.M. Qureshi. 1998. Effect of salinity on photosynthetic efficiency and yield of rice genotypes. Pak. J. Biol. Sci. 1:72-74.

Aslam, M., K. Ahmad, M.A. Maqbool, S. Bano, Q.U. Zaman and G.M. Talha. 2014. Assessment of adaptability in genetically diverse chickpea genotypes (Cicer arietinum L.) based on different physio morphological standards under ascochyta blight inoculation. Int. J. Adv. Res. 2:245-255.

Barea, J.M., R. Azcon and C. Azcon-Aguilar. 2005. Interactions between mycorrhizal fungi and bacteria to improve plant nutrient cycling and soil structure. In: F. Buscot and A. Varma (eds.), Microorganisms in Soils: Roles in Genesis and Functions. Springer, Berlin. pp. 195-212.

Barnard, J.H., L.D.V. Rensburg and A.T.P. Bennie. 2010. Leaching irrigated saline sandy to sandy loam apedal soils with water of a constant salinity. Irrig. Sci. 28:191201.

Bernstein, L. 1963. Osmotic adjustment of plants to saline media. II. Dynamic phase. Am. J. Bot. 48:909-918.

Carpici, E.B., N. Celika, G. Bayrama and B.B. Asikb. 2010. The effects of salt stress on the growth, biochemical parameter and mineral element content of some maize (Zea mays L.) cultivars. Afr. J. Biotechnol. 9:6937-6942. 
Cha-um, S. and C. Kirdmanee. 2009. Effect of salt stress on proline accumulation, photosynthetic ability and growth characters in two maize cultivars. Pak. J. Bot. 41:87-98.

Chavan, P.D. and B.A. Karadge. 1986. Growth, mineral nutrition, organic constituents and rate of photosynthesis in Sesbania grandiflora L. grown under saline conditions. Plant Soil. 93:395-404.

Chinnusamy, V., A. Jagendorf and J.K. Zhu. 2005. Understanding and improving salt tolerance in plants. Crop Sci. 45:437-448.

Desingh, R. and G. Kanagaraj. 2007. Influence of salinity stress on photosynthesis and antioxidative systems in two cotton varieties. Gen. Appl. Plant Physiol. 33:221-234.

Flowers, T.J. 2004. Improving crop salt tolerance. J. Exp. Bot. 55:307-319.

Gill, K.S. and O.S. Singh. 1989. Effect of salinity on growth, chemical composition and yield in paddy. Oryza. 26:162167.

Govt. of Pakistan. 2015. Economic Survey of Pakistan. 201516. Finance and Economic Affairs Division, Ministry of Finance, Govt. of Pakistan, Islamabad, Pakistan.

Gulzar, S., M.A. Khan and I.A. Ungar. 2003. Salt tolerance of a coastal salt marsh grass. Commun. Soil Sci. Plant Anal. 34:2595-2605.

Hameed, M., N. Naz, M.S.A. Ahmad, Islam-Ud-Din and A. Riaz. 2008. Morphological adaptations of some grasses from the salt range, Pakistan. Pak. J. Bot. 40:1571-1578.

Hussain, K., A. Majeed, K. Nawaz, K.H. Bhatti and F.K. Nisar. 2009. Effect of different levels of salinity on growth and ion contents of black seeds (Nigella sativa L.). Curr. Res. J. Biol. Sci. 1:135-138.

Hussain, K., M. Ashraf and M.Y. Ashraf. 2008. Relationship between growth and ion relation in pearl millet (Pennisetum glaucum (L.) R. Br.) at different growth stages under salt stress. Afr. J. Plant Sci. 2:23-27.

Hussain, M.M., L.K. Balbaa and M.S. Gaballah. 2007. Salicylic acid and salinity effects on growth of maize plants. Res. J. Agric. Biol. Sci. 3:321-328.

Karimi, G., M. Ghorbanli, H. Heidari, R.A. Khavarinejad and M.H. Assareh. 2005. The effects of $\mathrm{NaCl}$ on growth, water relations, osmolytes and ion content in Kochia prostrate. Biol. Plant. 49:301-304.

Koca, H., M. Bor, F. Ozdemir and I. Turkan. 2007. The effect of salt stress on lipid peroxidation, antioxidative enzymes and proline content of sesame cultivars. Environ. Exp. Bot. 60:344-351.

Mittler, R. 2002. Oxidative stress, antioxidants and stress tolerance. Trends Plant Sci. 7:405-410.

Mohammad, M., R. Shibli, M. Ajouni and L. Nimri. 1998. Tomato root and shoot responses to salt stress under different levels of phosphorus nutrition. J. Plant. Nutr. 21:1667-1680.
Moussa, H.R. 2006. Influence of exogenous application of silicon on physiological response of salt-stressed maize (Zea mays L.). Int. J. Agric. Biol. 2:293-297.

Munns, R. 2002. Comparative physiology of salt and water stress. Plant Cell Environ. 25:239-250.

Munns, R. and M. Tester. 2008. Mechanisms of salinity tolerance. Annu. Rev. Plant Biol. 59:651-681.

Munns, R., R.A. James and A. Lauchli. 2006. Approaches to increasing the salt tolerance of wheat and other cereals. J. Exp. Bot. 57:1025-1043.

Najafi, F., R.A. Khavari-Nejad, F. Rastgar-Jazii and M. Sticklen. 2007. Growth and some physiological attributes of pea (Pisum sativum L.) as affected by salinity. Pak. J. Biol. Sci. 10:2752-2755.

Pessarakli, M. and D.M. Kopec. 2009. Screening various ryegrass cultivars for salt stress tolerance. J. Food Agric. Environ. 7:739-743.

Qasim, M., M. Ashraf, M. Amir Jamil, M.Y. Ashraf and E.S.R. Shafiq-ur-Rehman. 2003. Water relations and leaf gas exchange properties in some elite canola (Brassica napus) lines under salt stress. Ann. Appl. Biol. 142:307316.

Serrano, R., J.M. Mullet, G. Rios, J.A. De Marquez, I. Larrinoa, M.P. Leube, I. Mendizabal, A.P. Ahuir, M. Proft, R. Ros and C. Montesinos. 1999. A glimpse of the mechanisms of ion homeostasis during salt stress. J. Exp. Bot. 50:1023-1036.

Sharma, S.K. 1995. Effect of salinity on growth performance and internal distribution of $\mathrm{Na}^{+}, \mathrm{K}^{+}$and $\mathrm{Cl}^{-}$in Vicia faba L. Ind. J. Plant Physiol. 38:69-72.

Steel, R.G.D., J.H. Torrie and D.A. Dickey. 1997. Principles and Procedures of Statistics: A biometrical approach, $3^{\text {rd }}$ Ed. McGraw Hill Book Co., Inc. New York.

Tammam, A.A., M.F.A. Alhamd and M.M. Hemeda. 2008. Study of salt tolerance in wheat (Triticum aestium L.) cultivar Banysoif 1. Aust. J. Crop Sci. 1:115-125.

Tejera, N., E. Ortega, R. Rodes and C. Lluch. 2006. Nitrogen compounds in the apoplastic sap of sugarcane stem: some implications in the association with endophytes. J. Plant Physiol. 163:80-85.

Tester, M. and R. Davenport. 2003. $\mathrm{Na}^{+}$tolerance and $\mathrm{Na}^{+}$ transport in higher plants. Ann. Bot. 91:503-507.

Turan, M.A., N. Turkmen and N. Taban. 2007. Effect of $\mathrm{NaCl}$ on stomatal resistance and proline, chlorophyll, $\mathrm{Na}, \mathrm{Cl}$ and $\mathrm{K}$ concentrations of lentil plants. J. Agron. 6:378381.

Veeranagamallaiah, G., P. Chandraobulreddy, G. Jyothsnakumari and C. Sudhakar. 2007. lutamine synthetase expression and pyrroline-5-carboxylate reductase activity influence proline accumulation in two cultivars of foxtail millet (Setaria italica L.) with differential salt sensitivity. Environ. Exp. Bot. 60:239244. 
Verma, S. and S.N. Mishra. 2005. Putrescine alleviation of growth in salt stressed Brassica juncea by inducing antioxidative defence system. J. Plant Physiol. 162:669677.
Wenxue, W., P.E. Bilsborrow, P. Hooley, D.A. Fincham, E. Lombi and B.P. Forster. 2003. Salinity induced differences in growth, ion distribution and partitioning in barley in between the cultivars Maythrope and its derived mutant Golden Promise. Plant Soil. 250:183-191. 